\title{
Three therapeutic regimens based on induction chemotherapy in locally advanced squamous cell carcinoma of the head and neck: a single center experience
}

\author{
Lin Jiang ${ }^{1}$, Liang Guo ${ }^{1}$, Kejing Wang ${ }^{1}$, Shengye Wang ${ }^{2}$, Meiyu Fang ${ }^{3}$, Jianlin Lou ${ }^{1}$ \\ ${ }^{1}$ Department of Head and Neck Surgery, ${ }^{2}$ Department of Radiotherapy, ${ }^{3}$ Department of Medical Oncology, Zhejiang Cancer Hospital, Hangzhou \\ 310022, China \\ Contributions: (I) Conception and design: L Jiang, J Lou; (II) Administrative support: J Lou; (III) Provision of study materials or patients: L Jiang, \\ L Guo, K Wang, S Wang, M Fang; (IV) Collection and assembly of data: L Jiang, L Guo, K Wang, S Wang, M Fang; (V) Data analysis and \\ interpretation: L Jiang; (VI) Manuscript writing: All authors; (VII) Final approval of manuscript: All authors. \\ Correspondence to: Jianlin Lou. Department of Head and Neck Surgery, Zhejiang Cancer Hospital, 1st Banshan East Road, Hangzhou 310022 , China. \\ Email: loujl@zjcc.org.cn.
}

\begin{abstract}
Background: This study aimed to compare three different therapeutic models based on regional control and the outcome of locally advanced squamous cell carcinoma of the head and neck (SCCHN) after induction chemotherapy (ICT).

Methods: One hundred and twenty patients with locally advanced SCCHN were retrospectively reviewed and divided into three groups. Patients in Group A received induction chemotherapy + concurrent chemoradiotherapy (ICT + CCRT). Patients in Group B received induction chemotherapy + radical surgery + adjuvant radiotherapy with or without chemotherapy (ICT + Surgery + RT/CRT). Patients in Group C received induction chemotherapy + planned neck dissection + concurrent chemoradiotherapy (ICT + PND + CCRT). The clinicopathological characteristics, locoregional recurrence (LR), distant metastasis (DM), and overall survival (OS) were compared among them.

Results: The median follow-up time was 20 months. In Group A, Group B and Group C, the 3-year OS was $69.7 \%, 72.9 \%$, and $65.5 \%$ respectively. The LR rate was $35.1 \%, 26.2 \%$, and $42.9 \%$, respectively. The DM rate was $10.5 \%, 31.0 \%$, and $9.5 \%$, respectively. There were no significant differences in OS and LR among three groups. The DM in Group B was significantly higher than that in Group $\mathrm{A}(\mathrm{P}<0.05)$, and was probably higher than that in Group $\mathrm{C}(\mathrm{P}=0.06)$.

Conclusions: Locally advanced SCCHN has a poor prognosis, and the first treatment is critical. Individualized therapeutic regimen based on the response of ICT could be an ideal solution. As cervical metastatic lymph nodes are less sensitive to ICT than primary tumors, PND before radiation therapy might improve the regional control and throat function preservation. A multidisciplinary team (MDT) collaboration is important throughout the treatment process.
\end{abstract}

Keywords: Squamous cell carcinoma; induction chemotherapy (ICT); concurrent chemoradiotherapy (CCRT); planned neck dissection (PND); multidisciplinary team (MDT)

Submitted Jul 04, 2019. Accepted for publication Nov 29, 2019.

doi: $10.21037 /$ tcr.2019.12.44

View this article at: http://dx.doi.org/10.21037/tcr.2019.12.44

\section{Introduction}

Squamous cell carcinoma of the head and neck (SCCHN) is one of the most common malignant tumors in the head and neck, accounting for nearly $5 \%$ of adult's newly diagnosed neoplasms, and it includes oral cavity, oropharyngeal, hypopharyngeal, laryngeal carcinomas and so on, depending on the primary lesions. As its special anatomical structure, 
head and neck tumors cover almost all functions related to pronunciation, speech, breathing, chewing, swallowing and etc. Patients with early-stage SCCHN (stage I-II) usually have favorable outcomes after radical surgery and/ or radiotherapy (RT) (1). Nevertheless, the majority of patients present with locally advanced lesions or metastatic cervical lymph nodes (stage III-IV) at diagnosis. A combination of surgery, RT and chemotherapy determined by a multidisciplinary team (MDT) has been recommended as a standard treatment for locally advanced SCCHN (1).

The initial treatment of locally advanced SCCHN is still controversial. It is very important that the physiological function and the quality of life should be preserved as much as possible while the tumor has been well controlled. The tumor foci, clinical staging, pathological subtype, changes on appearance and function, probable complications, patient's socio-economic status should be considered systematically. Concurrent chemoradiotherapy (CCRT) is becoming the preferred treatment for advanced SCCHN while possesses bigger advantages in preserving organ function. However, the Chinese population has poorer tolerance to the toxicity and side effects of CCRT. Although surgery, a traditional and classical treatment, might not be the preferred choice, it is still an important therapeutic strategy, especially for those who relapsed after initial chemoradiotherapy (CRT). Induction chemotherapy (ICT), as a part of comprehensive treatments, has got much attention in recent years because it not only increases throat preservation, but also reduces distant metastasis (DM) (2-4). ICT is generally not used to treat SCCHN patients independently but to screen patients before surgery or RT. The response degree can to some extent judge the sensitivity of RT and the overall efficiency.

Through searching for clinical practice and previous studies, we found that the sensitivity of cervical metastatic lymph nodes to ICT and CCRT was significantly lower than that of the primary foci. Cervical lymph node progression was one of the main causes of failure in the treatment of locally advanced SCCHN. Therefore, we recommended neck dissection (ND) before CCRT for such patients whose primary tumor was significantly reduced, but lymph nodes were not.

It could be more flexible to choose following treatment strategy based on the response of ICT. The present study was specifically targeted on the patients who were initially treated with ICT. One hundred and twenty patients with stage III-IV SCCHN were retrospectively reviewed, the survival outcomes and locoregional control were compared among these patients who received three different ICT based treatments.

\section{Methods}

\section{Patients}

From June 2013 to May 2017, there were totally 2,247 patients diagnosed with SCCHN and treated in our hospital. Eventually, 120 well-documented patients were screened out. These patients were defined as locally advanced SCCHN without DM (stage III, IVA, and IVB) according to the American Joint Committee of Cancer (AJCC) staging system (7th edition), and received initial ICT treatment. Primary lesions affected oral cavity, oropharynx, hypopharynx or larynx. In the final analysis, 120 patients were divided into three groups according to the therapeutic strategies (Table 1). This study had been approved by the Ethics Committee of our Hospital [zjzlyy Medical Ethics Approval Document (2015)-01-21].

\section{Treatments}

All patients received two courses of ICT previously. Two weeks after the second cycle, the response to ICT was estimated by imaging examination including CT and/or MRI. Patients were then divided into three different groups according to the effects of ICT. Patients in Group A (both primary tumor and lymph nodes were significantly reduced) received concurrent chemoradiotherapy (ICT + CCRT), patients in Group B (both primary tumor and lymph nodes were not reduced significantly) received radical surgery + adjuvant radiotherapy with or without chemotherapy (ICT + Surgery + RT/CRT), and patients in Group C (primary tumor was significantly reduced, but lymph nodes were not) received planned neck dissection + concurrent chemoradiotherapy (ICT + PND + CCRT) (See Figure 1).

ICT regimens were determined by the physicians in a MDT. PF (cisplatin and 5-fluorouracil), TP (docetaxel and cisplatin), and TPF (docetaxel, cisplatin and 5-fluorouracil) regimens were chosen based on patient's age, performance status, primary lesion, and differentiation of tumor. The therapeutic efficacy was evaluated after two courses of ICT according to RECIST 1.1 criteria (typical cases were shown as Figures 2-4).

Radical surgery included radical resection of the primary tumor and simultaneous ND. Modified ND was applicable for N1-N2 patients, while radical ND for N3 patients.

Dose of radical RT was 66-72 Gy, while adjuvant RT was 60-66 Gy determined by radiologists. All patients received intensity-modulated radiation therapy (IMRT). Cisplatin was used during CCRT as a classic regimen, while carboplatin acted as an alternative if patients were intolerant to cisplatin. 
Table 1 Clinicopathological characteristics of 120 patients with locally advanced SCCHN

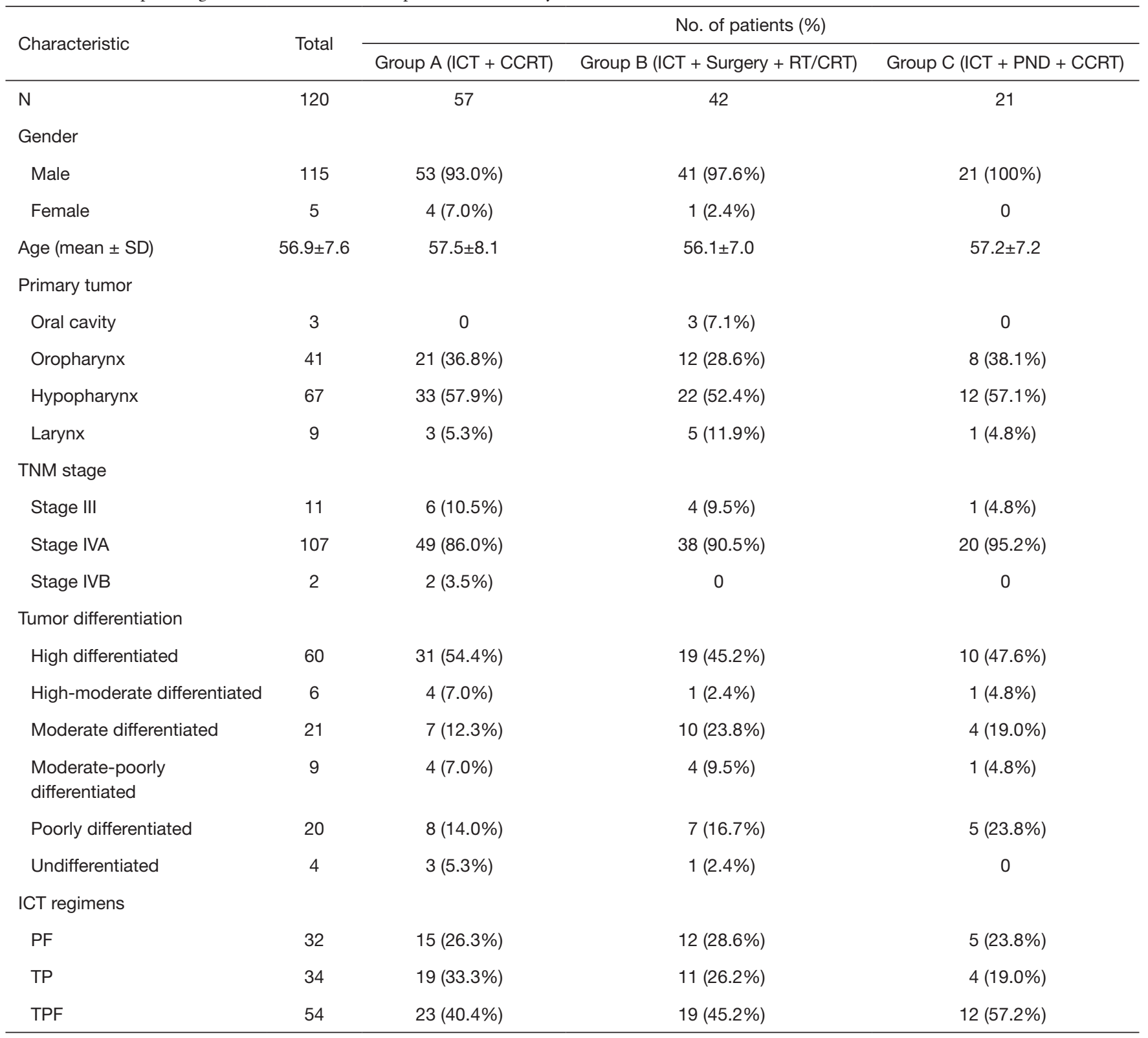

Patients in Group A received induction chemotherapy + concurrent chemoradiotherapy, patients in Group B received induction chemotherapy + radical surgery + adjuvant radiotherapy with or without chemotherapy, patients in Group C received induction chemotherapy + planned neck dissection + concurrent chemoradiotherapy. TNM stage was determined according to the 7th edition of American Joint Committee of Cancer (AJCC) staging system. ICT regimens: PF, cisplatin and 5-fluorouracil; TP, docetaxel and cisplatin; TPF, docetaxel, cisplatin and 5-fluorouracil.

\section{Follow-up}

After completion of treatments, all patients were followed up once every 3 months in the first 2 years, and thereafter once every 6 months in the following years. The followup periods were calculated from the date of completion of primary treatment to death or the last follow-up time. During the observation process, physical examination, laboratory examination, and imaging examination (including ultrasonography, endoscopy, CT or MRI) were routinely performed. If patients were diagnosed with recurrence or metastasis, further treatments such as 


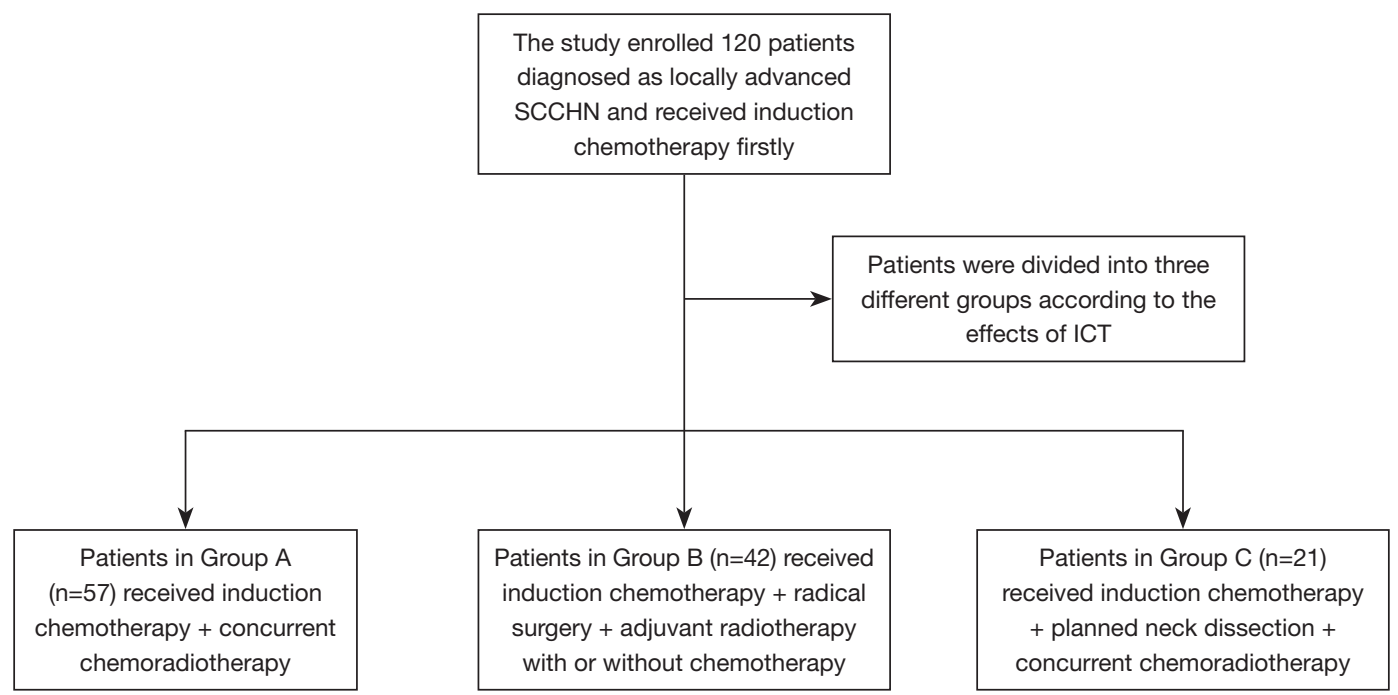

Figure 1 Flowchart of patients' grouping and treatments. ICT, induction chemotherapy.
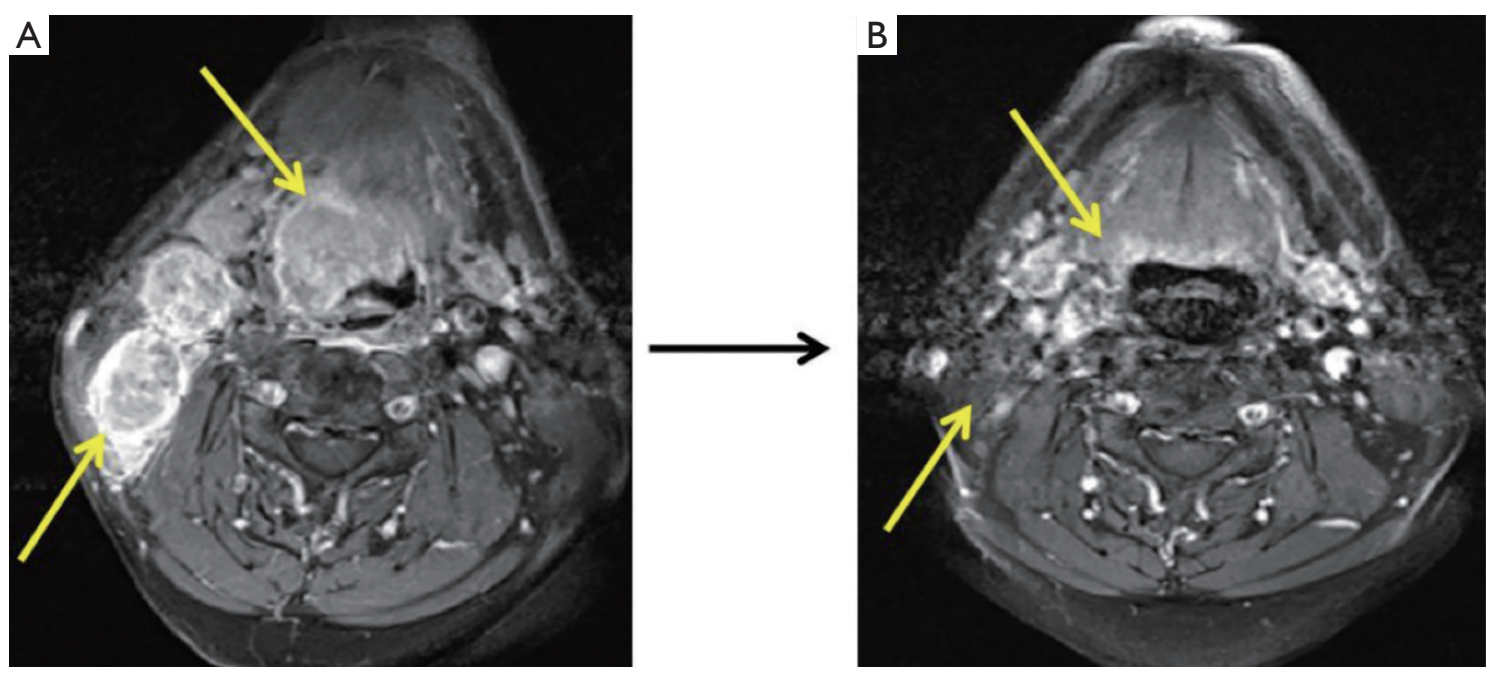

Figure 2 Typical case 1: before therapy, MRI image showed the tumor of right tongue root and the metastatic lymph node in right neck (A, upper yellow arrow showed the primary tumor, lower yellow arrow showed the metastatic lymph node); after 2 courses of ICT, MRI image showed both primary tumor and metastatic lymph node approached CR (B, upper yellow arrow showed the primary tumor, lower yellow arrow showed the metastatic lymph node). Case 1 received ICT + CCRT.

salvage surgery, palliative RT, palliative chemotherapy, targeted therapy, or best supportive care were employed individually.

\section{Statistical analysis}

The main endpoint was overall survival (OS, calculated from the date of diagnosis to death or the last follow-up time). The secondary endpoints included locoregional recurrence (LR) and DM. Statistical analysis were performed with SPSS version 20.0 for Windows (IBM, Armonk, USA). Kaplan-Meier curves and Log rank test were used to describe OS. Chi-square test was used to compare the $\mathrm{LR}$ and $\mathrm{DM}$. A value of $\mathrm{P}<0.05$ was considered 

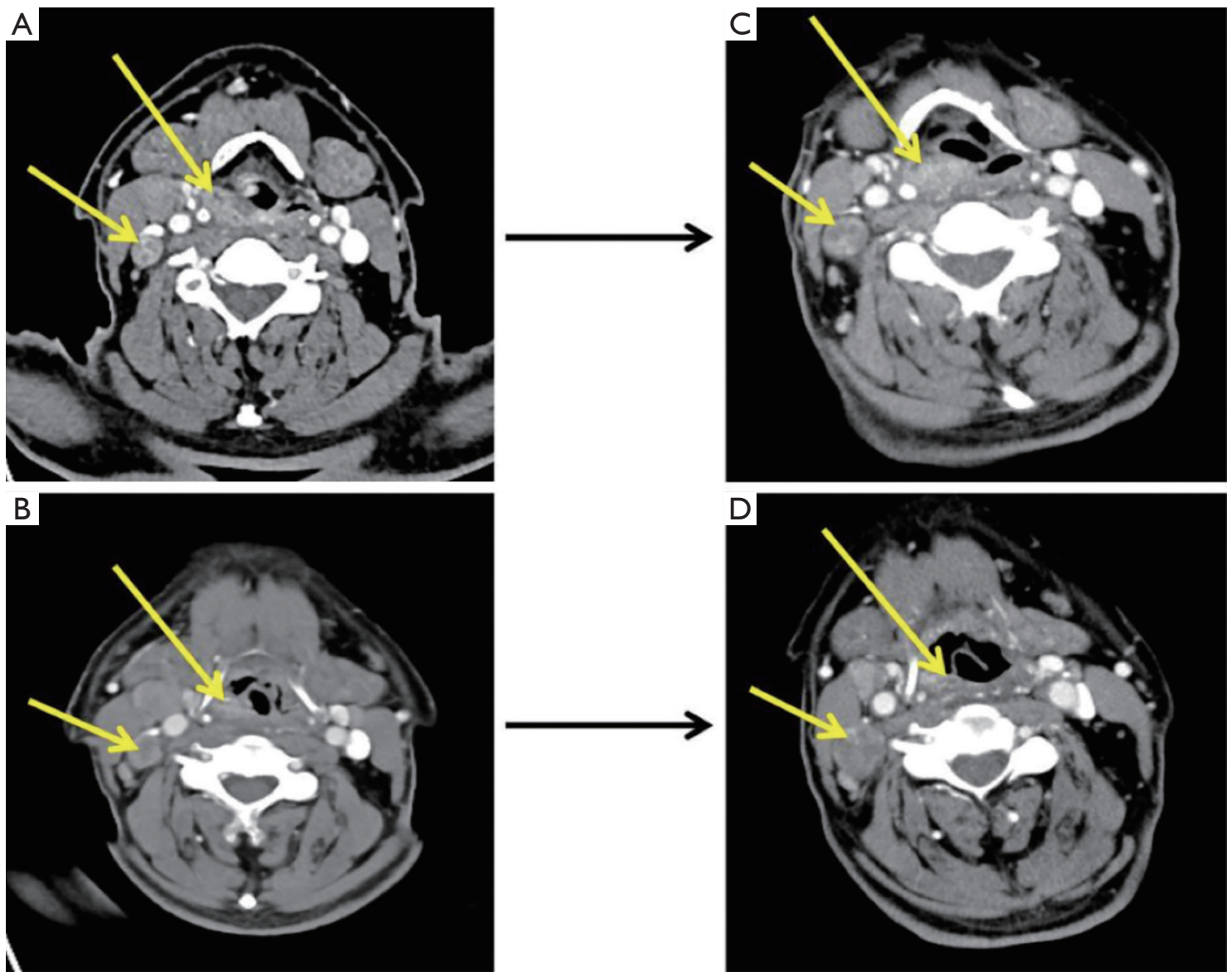

Figure 3 Typical case 2: before therapy, CT scan showed the tumor of right hypopharynx and the metastatic lymph node in right neck (A,B, upper yellow arrow showed the primary tumor, lower yellow arrow showed the metastatic lymph node); after 2 courses of ICT, CT scan showed the primary tumor maintained SD, while the metastatic lymph node reached to PD (C,D, upper yellow arrow showed the primary tumor, lower yellow arrow showed the metastatic lymph node). Case 2 received ICT + Surgery + CRT.

statistically significant.

\section{Results}

\section{Clinicopathological characteristics}

Eventually, 120 well-documented patients were included in final analysis (Table 1). The median follow-up time was 20 months (ranged from 1 to 56 months). There were thirty-five patients died, the death rate was $29.2 \%$. Twentyseven patients died of tumor progression, and 8 patients died of disease-related or treatment-related complications described as follows: 3 patients died of respiratory failure due to pulmonary infection, 2 patients died of sudden unconsciousness, 2 patients died of sudden dyspnea, and 1 patient died of cervical hemorrhage.

\section{Response of ICT}

After two courses of ICT, tumor loci were evaluated by CT or MRI according to RECIST 1.1 criteria. There were 19 patients (11 in group A, 8 in group C) received CR, 85 patients (45 in group A, 27 in group B, 13 in group C) received PR, and 16 patients (1 in group A, 15 in group B) maintained SD of primary tumor. 1 patient from group A received CR, 85 patients (47 in group $\mathrm{A}, 23$ in group $\mathrm{B}, 15$ in group $\mathrm{C}$ ) received $\mathrm{PR}, 23$ patients ( 3 in group A, 14 in group B, 6 in group C) maintained SD, and 1 patient from group $B$ reached $\mathrm{PD}$ of metastatic cervical lymph nodes. In addition, 10 patients were assessed as $\mathrm{cN} 0$ (Table 2).

\section{LR and DM}

Twenty patients in Group A, 11 in Group B, and 9 in 

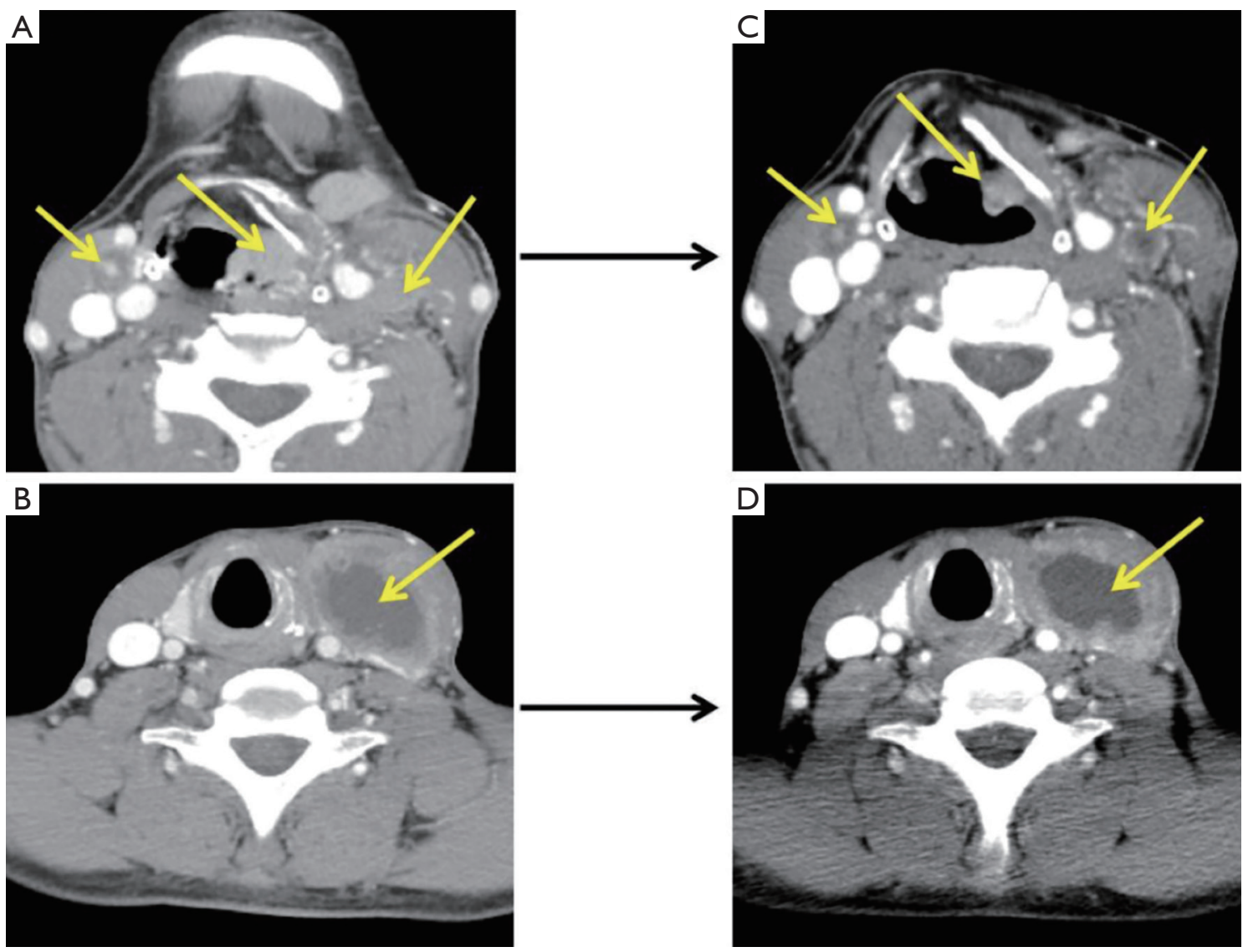

Figure 4 Typical case 3: before therapy, CT scan showed the tumor of left hypopharynx and the metastatic lymph nodes in bilateral neck (A,B, yellow arrow in the middle showed the primary tumor, yellow arrows on both sides showed the metastatic lymph nodes); after 2 courses of ICT, CT scan showed the primary tumor significantly achieved PR, while the metastatic lymph nodes maintained SD (C,D, yellow arrow in the middle showed the primary tumor, yellow arrows on both sides showed the metastatic lymph nodes). Case 3 received $\mathrm{ICT}+\mathrm{PND}+\mathrm{CCRT}$.

Group C developed LR. Six patients in Group A, 13 in Group B, and 2 in Group C developed DM. The main site of DM was lung, followed by the bone and liver, and skin metastasis was rare. There was no significant difference in the LR among three groups. The incidence of $\mathrm{DM}$ in Group B was significantly higher than Group A $(\mathrm{P}<0.05)$ and was probably higher than Group $\mathrm{C}(\mathrm{P}=0.06)$ (Table 3).

\section{Supplementary treatment}

There were totally forty patients suffered LR, 21 of whom received salvage operations. Twelve patients (5 cervical lymph nodes recurrence and 7 local tumor recurrence) were well controlled after surgery.

\section{Survival outcome}

Sixteen (28.1\%) patients in Group A, 12 (28.6\%) in Group B, and $7(33.3 \%)$ in Group C died in our research, there was no significant difference in the mortality among three groups $(\mathrm{P}=0.897)$. The total 3 -year OS was $69.7 \%$. In Group A, Group B and Group C, the 3-year OS was $69.7 \%, 72.9 \%$, and $65.5 \%$ respectively. Neither, there was no significant difference in OS (see Figure 5).

\section{Discussion}

Locally advanced SCCHN usually has a poor prognosis, of which the reported 5 -year OS is about $50 \%$ or even lower. The majority of patients will develop LR and/or DM, 
Table 2 Response of induction chemotherapy of three groups

\begin{tabular}{lccc}
\hline Characteristic & $\begin{array}{c}\text { Group A } \\
\text { (ICT + CCRT) }\end{array}$ & $\begin{array}{c}\text { Group B } \\
\text { (ICT + surgery } \\
+ \text { RT/CRT) }\end{array}$ & $\begin{array}{c}\text { Group C } \\
\text { (ICT + PND } \\
+ \text { CCRT })\end{array}$ \\
\hline $\mathrm{N}$ & 57 & 42 & 21 \\
CR (PT/LN) & $11 / 1$ & $0 / 0$ & $8 / 0$ \\
PR (PT/LN) & $45 / 47$ & $27 / 23$ & $13 / 15$ \\
SD (PT/LN) & $1 / 3$ & $15 / 14$ & $0 / 6$ \\
PD (PT/LN) & $0 / 0$ & $0 / 1$ & $0 / 0$ \\
CN0* & 6 & 4 & 0 \\
\hline
\end{tabular}

*, 10 patients were assessed as cNO by CT and/or MRI image before initial treatment. ICT, induction chemotherapy; CCRT, concurrent chemoradiotherapy; CRT, chemoradiotherapy; PND, planned neck dissection; PT, primary tumor; LN, lymph node.

Table 3 Locoregional recurrence and distant metastasis of three groups

\begin{tabular}{lcccc}
\hline Characteristic & $\begin{array}{c}\text { Group A } \\
\text { (ICT + } \\
\text { CCRT) }\end{array}$ & $\begin{array}{c}\text { Group B } \\
(\text { ICT + surgery } \\
+ \text { RT/CRT) }\end{array}$ & $\begin{array}{c}\text { Group C } \\
(\text { ICT + PND } \\
+ \text { CCRT })\end{array}$ & P value \\
\hline $\mathrm{N}$ & 57 & 42 & 21 & \\
$\begin{array}{l}\text { Local } \\
\text { recurrence }\end{array}$ & $13(22.8 \%)$ & $6(14.3 \%)$ & $6(28.6 \%)$ & 0.370 \\
$\begin{array}{l}\text { Regional } \\
\text { recurrence }\end{array}$ & $12(21.1 \%)$ & $6(14.3 \%)$ & $4(19.0 \%)$ & 0.688 \\
$\begin{array}{l}\text { Locoregional } \\
\text { recurrence }\end{array}$ & $20(35.1 \%)$ & $11(26.2 \%)$ & $9(42.9 \%)$ & 0.387 \\
$\begin{array}{l}\text { Distant } \\
\text { metastasis }\end{array}$ & $6(10.5 \%)$ & $13(31.0 \%)$ & $2(9.5 \%)$ & $0.011^{*}$ \\
\hline
\end{tabular}

*, P=0.011<0.05: Group B vs. Group A. ICT, induction chemotherapy; CCRT, concurrent chemoradiotherapy; CRT, chemoradiotherapy; PND, planned neck dissection.

especially within the first 2 years after primary therapy $(5,6)$. In our research, the total LR rate was $33.3 \%$ (40/120), and the median time of LR was 8 months. The success rate of salvage operation was only about $50 \%$.

ICT, though does not show benefit in extending OS, has already been firmly proven to decrease tumor stage, improve surgical resection, preserve organ functions, and reduce DM $(2-4,7)$. Platinum-based combination chemotherapy regimens have been widely used in clinical practice. In recent years, a number of clinical trials have confirmed that TPF regimen (docetaxel, cisplatin and 5-fluorouracil) may achieve a higher rate of remission without significantly increasing severe adverse reactions $(2,8-10)$. Currently, TPF regimen is becoming the first choice of ICT for locally advanced SCCHN.

Another important role of ICT is to predict the effectiveness of subsequent radiation/chemoradiation therapy $(11,12)$. According to NCCN guideline, the efficacy of ICT determines the use of following treatment. Patients with complete remission (CR) after primary therapy will receive radical RT or CCRT, and patients with partial remission (PR) may receive CCRT or surgery. For those without remission, surgery should be the proper option. In this study, the remission rates of primary tumor were $94.9 \%$ in Group A, $62.8 \%$ in Group B, and $95.5 \%$ in Group C, respectively.

In subgroup analysis, the courses of ICT before CCRT did not affect the outcome. The LR, DM and OS were comparable between patients receiving $\leq 2$ courses of ICT and those undergoing $\geq 3$ courses of ICT. This was consistent with previously reported (13). However, there were evidence showing that the frequency of ICT may affect the prognosis $(14,15)$. Indeed, for patients tolerable to ICT, 2 to 4 courses before RT or CRT are acceptable.

Of note, metastatic cervical lymph nodes are less sensitive to ICT than primary tumors, which might be ascribed to the different biologic characteristics. In this study, the lymph nodes remission rates were $84.8 \%$ in Group A, $53.5 \%$ in Group B and $68.2 \%$ in Group C, respectively. Patients in Group C received ND before RT (so-called planned neck dissection, PND). Some research showed that ND before RT can improve DFS and PFS (16-18). In another research of our department, we found priority of PND before RT in regional control for those with lymph nodes metastases insensitive to ICT (19). Moreover, the effectiveness of ICT can be further determined by pathological examination of lymph nodes, by which the radiation dose of cervical lymphatic drainage area can be calculated precisely so as to reduce the complications.

In the present study, the DM rate of Group B was significantly higher than Group A, and also, although not significantly, higher than Group C. We can infer that patients have poor response to chemotherapy might occur recurrence and metastasis easier. However, the death rate and the 3-year OS of Group B were not worse than other two groups, which was attributed to second-line chemotherapy, molecule-targeted therapy (Cetuximab, Nituzumab, or Bevacizumab), and the best supportive treatments including nutrition and analgesia (20-22).

Both international guideline and domestic expert consensus recommend MDT collaboration in the treatment of stage III, IVA, and IVB patients. In our institution, 

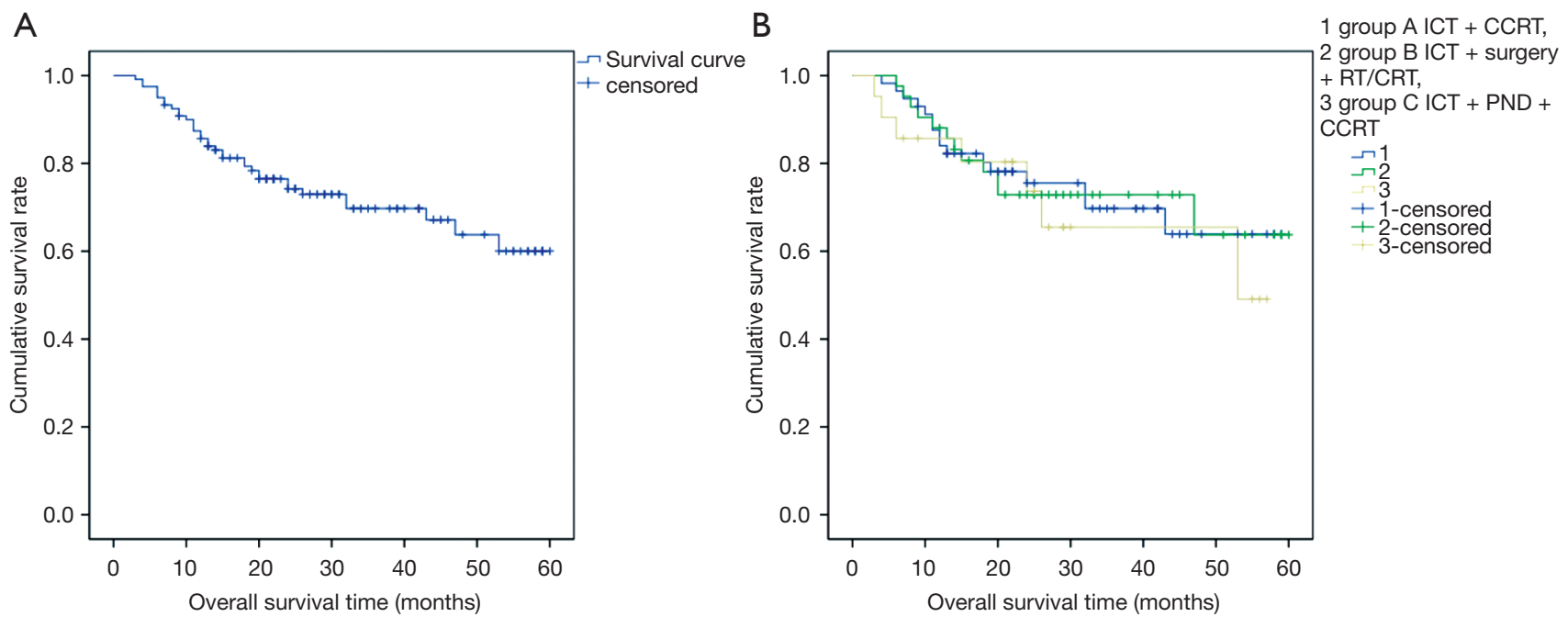

Figure 5 Survival curve of all enrolled patients (A). Kaplan-Meier curves showed there was no significant difference among three groups (Log rank test, $\mathrm{P}=0.835$ ) (B). ICT, induction chemotherapy; CCRT, concurrent chemoradiotherapy; CRT, chemoradiotherapy; PND, planned neck dissection.

Individualized therapeutic plan has been made in consideration of tumor stage, physical performance, organ function preservation, financial status, and cultural customs.

\section{Conclusions}

In conclusion, for patients with locally advanced SCCHN, the integrity and thoroughness of primary treatment is very important. Individualized therapeutic regimen based on the response of ICT could be an ideal solution. As metastatic cervical lymph nodes are less sensitive to ICT than primary tumors, PND before CCRT might improve the regional control, preserve throat function, and lead to better quality of life. A MDT collaboration is necessary throughout the treatment process.

\section{Acknowledgments}

We would like to thank all the members of multidisciplinary team and specialist nursing team of Head and Neck Cancer Center of our department.

Funding: This study was supported by the Major Science and Technology Projects of Zhejiang Medical and Health Program (No. WKJ-ZJ-1712 and 2015ZDA007), the General Research Projects of Zhejiang Medical and Health Program (No. 2017KY029), and Zhejiang Administration of Traditional Chinese Medicine Foundation (No. 2018ZB025).

\section{Footnote}

Conflicts of Interest: The authors have completed the ICMJE uniform disclosure form (available at http://dx.doi. org/10.21037/tcr.2019.12.44). The authors have no conflicts of interest to declare.

Ethical Statement: The authors are accountable for all aspects of the work in ensuring that questions related to the accuracy or integrity of any part of the work are appropriately investigated and resolved. The study was conducted in accordance with the Declaration of Helsinki (as revised in 2013). This study had been approved by the Ethics Committee of our Hospital [zjzlyy Medical Ethics Approval Document (2015)01-21]. Informed consent was waived due to the retrospective nature of the study.

Open Access Statement: This is an Open Access article distributed in accordance with the Creative Commons Attribution-NonCommercial-NoDerivs 4.0 International License (CC BY-NC-ND 4.0), which permits the noncommercial replication and distribution of the article with the strict proviso that no changes or edits are made and the original work is properly cited (including links to both the formal publication through the relevant DOI and the license). See: https://creativecommons.org/licenses/by-nc$\mathrm{nd} / 4.0 /$. 


\section{References}

1. China Cancer Association Head and Neck Cancer Specialized Committee. Expert Consensus on Comprehensive Treatment of Head and Neck Tumors. World J Otorhinolaryngol Head Neck Surg 2010;45:535-41.

2. Chapman $\mathrm{CH}$, Parvathaneni U, Yom SS. Revisiting induction chemotherapy before radiotherapy for head and neck cancer, part I: carcinoma of non-nasopharyngeal sites. Future Oncol 2017;13:469-75.

3. Haddad RI, Posner M, Hitt R, et al. Induction chemotherapy in locally advanced squamous cell carcinoma of the head and neck: role, controversy, and future directions. Ann Oncol 2018;29:1130-40.

4. Vidal L, Ben Aharon I, Limon D, et al. Role of Induction Chemotherapy Prior to Chemoradiation in Head and Neck Squamous Cell Cancer-Systematic Review and Meta-analysis. Cancer J 2017;23:79-83.

5. Li XM, Di B, Shang YD, et al. Value of postoperative radiation therapy for regional control after dissection in head and neck squamous cell carcinoma cases. Asian Pac J Cancer Prev 2013;14:4273-8.

6. Teymoortash A, Werner JA. Current advances in diagnosis and surgical treatment of lymph node metastasis in head and neck cancer. GMS Curr Top Otorhinolaryngol Head Neck Surg 2012;11:Doc04.

7. Iocca O, Farcomeni A, Di Rocco A, et al. Locally advanced squamous cell carcinoma of the head and neck: A systematic review and Bayesian network meta-analysis of the currently available treatment options. Oral Oncol 2018;80:40-51.

8. Ghi MG, Paccagnella A, Ferrari D, et al. Induction TPF followed by concomitant treatment versus concomitant treatment alone in locally advanced head and neck cancer. A phase II-III trial. Ann Oncol 2017;28:2206-12.

9. Haddad R, Tishler R, Wirth L, et al. Rate of pathologic complete responses to docetaxel, cisplatin, and fluorouracil induction chemotherapy in patients with squamous cell carcinoma of the head and neck. Arch Otolaryngol Head Neck Surg 2006;132:678-81.

10. Lowe NM, Bernstein JM, Mais K, et al. Taxane, platinum and 5-FU prior to chemoradiotherapy benefits patients with stage IV neck node-positive head and neck cancer and a good performance status. J Cancer Res Clin Oncol 2018;144:389-401.

11. de Bree R, Wolf GT, de Keizer B, et al. Response assessment after induction chemotherapy for head and neck squamous cell carcinoma: From physical examination to modern imaging techniques and beyond. Head Neck 2017;39:2329-49.

12. Kiong KL, de Souza NN, Sultana R, et al. Meta-analysis of induction chemotherapy as a selection marker for chemoradiation in the head and neck. Laryngoscope 2018;128:1594-601.

13. Lv JW, Qi ZY, Zhou GQ, et al. Optimal cumulative cisplatin dose in nasopharyngeal carcinoma patients receiving additional induction chemotherapy. Cancer Sci 2018;109:751-63.

14. Fangzheng W, Quanquan S, Chuner J, et al. Gemcitabine/ cisplatin induction chemotherapy before concurrent chemotherapy and intensity-modulated radiotherapy improves outcomes for locoregionally advanced nasopharyngeal carcinoma. Oncotarget 2017;8:96798-808.

15. Zhang Y, Chen M, Chen C, et al. The efficacy and toxicities of intensive induction chemotherapy followed by concurrent chemoradiotherapy in nasopharyngeal carcinoma patients with N3 disease. Sci Rep 2017;7:3668.

16. Cupino A, Axelrod R, Anne PR, et al. Neck dissection followed by chemoradiotherapy for stage IV $\left(\mathrm{N}_{+}\right)$oropharynx cancer. Otolaryngol Head Neck Surg 2007;137:416-21.

17. Jeong WJ, Jung EJ, Hah JH, et al. Preliminary results of pre-radiation neck dissection in head and neck cancer patients undergoing organ preservation treatment. Acta Otolaryngol Suppl 2007;(558):121-7.

18. Paximadis PA, Christensen ME, Dyson G, et al. Up-front neck dissection followed by concurrent chemoradiation in patients with regionally advanced head and neck cancer. Head Neck 2012;34:1798-803.

19. Jiang L, Lou JL, Wang KJ, et al. [Planned neck dissection in the treatment of locally advanced head and neck squamous cell carcinoma]. Zhonghua Er Bi Yan Hou Tou Jing Wai Ke Za Zhi 2018;53:92-6.

20. Lala M, Chirovsky D, Cheng JD, et al. Clinical outcomes with therapies for previously treated recurrent/metastatic head-and-neck squamous cell carcinoma (R/M HNSCC): A systematic literature review. Oral Oncol 2018;84:108-20.

21. Posch D, Fuchs H, Kornek G, et al. Docetaxel plus cetuximab biweekly is an active regimen for the first-line treatment of patients with recurrent/metastatic head and neck cancer. Sci Rep 2016;6:32946.

22. Specenier P, Vermorken JB. Optimizing treatments for recurrent or metastatic head and neck squamous cell carcinoma. Expert Rev Anticancer Ther 2018;18:901-15.

Cite this article as: Jiang L, Guo L, Wang K, Wang S, Fang M, Lou J. Three therapeutic regimens based on induction chemotherapy in locally advanced squamous cell carcinoma of the head and neck: a single center experience. Transl Cancer Res 2020;9(2):901-909. doi: 10.21037/tcr.2019.12.44 